\title{
Driving retirement: the role of the physician
}

\author{
David B. Carr, Thomas M. Meuser, John C. Morris
}

$\infty$

See related articles, pages 575 and 59I

I $\mathrm{n}$ the United States, licensed drivers over the age of 65 years today number more than 20 million - a figure that will increase substantially over the next few decades. ${ }^{1}$ Certain age-associated conditions such as dementia will lessen the expected increase, since, for reasons of safety, the people affected require earlier retirement from driving. For those diagnosed with Alzheimer's disease, the most common cause of dementia in late life, it is not a matter of if retirement from driving will be necessary, but simply when.

That "when" can be difficult to determine, however, because valid and reliable methods to assess fitness to drive are lacking ${ }^{2}$ and little is known about individual, family and health-related factors that motivate driving cessation in patients with dementia. ${ }^{3}$ Herrmann and colleagues ${ }^{4}$ have provided a welcome addition to the paucity of literature on this topic. They analyzed data from patients referred to subspecialists in the Canadian Outcomes Study in Dementia ${ }^{5}$ to determine baseline factors that predicted driving cessation in older adults with Alzheimer's disease or other dementias. The study had several strengths, including its prospective design and its use of accepted clinical diagnostic criteria and assessment tools to quantify dementia-related impairment.

Their findings that dementia severity and advanced age are associated with driving cessation confirmed results from other studies. Moreover, they demonstrated that level of cognitive impairment and behaviours such as agitation, apathy and hallucinations were found to be significant specific predictors of driving cessation in patients with mild-to-moderate dementia. Interestingly, at about 2 years after inclusion in the study (and therefore 2 years or more after diagnosis), $50 \%$ of these patients with dementia were still driving. That observation suggests that even in clinical settings, driving cessation does not necessarily occur promptly.

Also interesting is their finding of the differential impact of psychiatric symptoms. The presence of hallucinations and apathy appear to hasten retirement from driving, whereas agitation and aggression appear to have the opposite effect. Because hallucinations are associated with more severe dementia, it is unsurprising that people who experience this complication are likely to cease driving. However, agitation and aggression also are associated with more advanced dementia. Perhaps families and physicians were reticent to confront people who display these symptoms, or perhaps such individuals tend to be more resistive to the recommendation to cease driving. The loss of personal awareness and lack of insight into cognitive and functional deficits that is common among people with dementia probably also interfere with their capacity to appreciate the need for driving retirement.

This study also had several limitations. Although the overall sample in the project was large, this article focuses primarily

on the subset of individuals $(n=203)$ who still were driving at their first assessment. It is unclear how the findings generalize beyond this subgroup. Although the investigators mention diagnosing non-Alzheimer dementias, no data are presented on the frequency of these other dementing disorders in the sample. It is possible that dementia with Lewy bodies (which produces hallucinations) and frontotemporal dementia (often symptomized by apathy) could contribute to the association of these features with driving retirement. Inclusion of separate diagnostic categories could provide a window on risk factors for driving cessation in specific subtypes of dementia.

Many medical and nonmedical factors that could affect driving retirement were not systematically examined. Medical illnesses appear to play an important role in reducing one's ability to drive safely and therefore prompt driving retirement. ${ }^{6}$ Although the investigators mention data on visual acuity as another condition of interest, there apparently was no review of patient records to document additional medical conditions or physical disabilities that could influence driving cessation. A determination of the possible association between polypharmacy or sedating medications and driving retirement would have been useful.

Noncognitive factors are important influences on driving cessation among people with Alzheimer's disease. ${ }^{7}$ The personality types of the driver and caregiver, the need for a licensed driver in the household, lack of insight, prior level of driving activity, and the relationship and proximity of family members all may relate to driving cessation, but were not examined in this study. Because people who have been active drivers throughout their lives are also more likely to continue driving than infrequent drivers, ${ }^{8}$ exposure and miles travelled would have been additional important variables to consider and measure.

The authors acknowledged that they did not determine who played a major role in the decision to cease driving. In one oft-cited study of drivers with Alzheimer's disease, ${ }^{9}$ the primary impetus for driving retirement came from pressure exerted by family members, although physicians were also frequently involved. Just how influential physicians can be in encouraging patients to stop driving needs more study.

Finally, the study incorporated no assessment of driving fitness, which makes it difficult to know whether the patients who stopped driving were indeed at risk and should have retired. It is therefore unclear how this information will be of practical use to physicians or to the licensing authorities.

How, then, is the clinician to act in this important realm? It has been suggested that counselling for driving retirement and identifying alternative methods of transportation should be discussed early in the care process for dementia, well before a crisis occurs. ${ }^{10}$ Several resources exist to help clinicians assess older adults and drivers with cognitive impairment (e.g., www.ama-assn.org/ama/pub/category/I079I.html and 
www.candrive.ca/En/About/what_candrive.asp), to weigh the legal and ethical responsibilities in this difficult area, and to broach the topic of driving retirement and move toward a workable plan. The Hartford Insurance Corporation, for example, offers 2 free publications that make excellent patient handouts: At the crossroads: a guide to Alzheimer's disease, dementia and driving (available at www.thehartford.com (alzheimers) and We need to talk: family conversations with older drivers (www.thehartford.com/talkwitholderdrivers). Community organizations, such as the Alzheimer's Association, also can assist with driving retirement issues. Individualized transportation options are needed for older adults with dementia who do not have an informal network of family or social contacts that can fulfill this role. Meanwhile, physicians should know the laws and reporting requirements for unsafe drivers in their province or state, and work proactively with patients and their families to achieve driving retirement before serious problems occur.

This article has been peer reviewed.

From the Divisions of Geriatrics (Carr) and Neurology (Meuser, Morris), Department of Medicine and the Alzheimer's Disease Research Center, Washington University in St. Louis School of Medicine, St. Louis, Mo.

Competing interests: David Carr is a consultant for the American Medical Association. John Morris has been involved in clinical trials of antidementia drugs sponsored by Elan and by Eli Lilly and Company, and has accepted consultancy fees or speaking honoraria from Amgen, AstraZeneca, Axonyx, Elan, Genworth, Myriad, Novartis and Sanofi-Aventis.
Contributors: This article was written and revised as a cooperative effort by all authors, all of whom approved the version to be published.

Acknowledgements: This commentary was supported by National Institute on Aging (Bethesda, Md.) grants P50 AG0568I and Por AG0339I.

\section{REFERENCES}

I. Fain M. Should older drivers have to prove that they are able to drive? Arch Intern Med 2003; 163:2126-8.

2. Meuser T, Carr DB, Berg-Weger M, et al. Driving and dementia in older adults implementation and evaluation of a continuing education project. Gerontologist 2006;46(5). In press.

3. Perkinson MA, Berg-Weger ML, Carr DB, et al. Driving and dementia of the Alzheimer type: beliefs and cessation strategies among stakeholders. Gerontologist 2005; $45: 676-85$.

4. Herrmann N, Rapoport MJ, Sambrook R, et al. Predictors of driving cessation in mild to moderate dementia. CMAJ 2006;I75(6):59I-5.

5. Sambrook R, Herrmann N, Hebert R, et al. Canadian Outcomes Study in Dementia: study methods and patient characteristics. Can J Psychiatry 2004;49:417-27.

6. Gilhotra JS, Mitchell P, Ivers R, et al. Impaired vision and other factors associated with driving cessation in the elderly: the Blue Mountains Eye Studyx. Clin Experiment Ophthalmol 200I;29:104-7.

7. Carr DB, Shead V, Storandt M. Driving cessation in older adults with DAT. Gerontologist 2005; $45: 824-7$.

8. Hakamies-Blomqvist L, Siren A. Deconstructing a gender difference: driving cessation and personal driving history of older women. J Safety Res 2003;34:383-8.

9. Trobe JD, Waller PF, Cook-Flanagan CA, et al. Crashes and violations among drivers with Alzheimer disease. Arch Neurol I996;53:4II-6.

Io. Staplin L, Hunt L. Driver programs: transportation in an aging society. Washington: Transportation Research Board; 2004. p. 69-94.

Correspondence to: Dr. John C. Morris, Alzheimer Disease Research Center, 4488 Forest Park Avenue, Suite I6o, St. Louis MO 63108; fax 314 286-2763; morrisj@abraxas.wustl.edu

\section{Understanding the health of Indigenous peoples in Canada: key methodological and conceptual challenges}

\section{Janet Smylie, Marcia Anderson}

$\mathrm{O}$ ver the past year I have had the privilege of working with Métis elder and author Maria Campbell and 2 northern Saskatchewan communities on an oral history project. The project, "Kokum, what makes a baby well?" is designed to archive historic understandings of infant wellness and see if there are concepts that can be meaningfully applied to the measurement of infant health today.

Several months ago, we were working through the Cree translation of the project consent forms. As we came to the term "health measurement," Maria knitted her brow and told of me, "There is no word in Cree for this. There is a word for . 'measurement,' but we use it to talk about the amount of wood cut or the size of a catch of fish."

For more than a decade, health researchers have systematically documented inequities in health status between Aboriginal and non-Aboriginal Canadians. ${ }^{1-3}$ In this article, we highlight several key challenges that affect the collection, in- terpretation, and application of Aboriginal health assessment data in Canada. These include data coverage and quality; data jurisdiction and utility; data governance and relevance; and infrastructure and human resource capacity.

\section{Data coverage and quality}

Monitoring health status to "identify and solve community health problems" tops the American Public Health Association's list of essential services. ${ }^{4}$ Health assessment data are drawn from 5 principal sources: census, vital registration, health surveys, health services utilization data and surveillance systems. A basic epidemiologic tenet is that, when populationbased rates are calculated from these data sources, enumeration of the population of interest should be as complete as possible; and the count of the event of interest in that population, as accurate as possible. Rates based on incomplete enu- 